This item was submitted to Loughborough's Research Repository by the author.

Items in Figshare are protected by copyright, with all rights reserved, unless otherwise indicated.

\title{
Detecting heritage crime(s): What we know about illicit metal detecting in
}

\section{England and Wales}

\section{PLEASE CITE THE PUBLISHED VERSION}

\section{PUBLISHER}

Cambridge University Press (CUP)

VERSION

AM (Accepted Manuscript)

\section{PUBLISHER STATEMENT}

This paper was accepted for publication in the journal International Journal of Cultural Property and the definitive published version is available at https://doi.org/10.1017/s0940739119000158

\section{LICENCE}

CC BY-NC-ND 4.0

\section{REPOSITORY RECORD}

Daubney, Adam, and Louise Nicholas. 2019. "Detecting Heritage Crime(s): What We Know About Illicit Metal Detecting in England and Wales". figshare. https://hdl.handle.net/2134/9975971.v1. 
Detecting Heritage Crime(s): What We Know about Illicit Metal Detecting in England and Wales

\author{
Adam Daubney \\ Portable Antiquities Scheme, Lincolnshire County Council, Lancaster House, Orchard \\ Street, Lincoln, United Kingdom; Email: adam.daubney@lincolnshire.gov.uk
}

Louise Nicholas

Department of Social Sciences, Loughborough University, Loughborough, United Kingdom; Email: I.e.nicholas@lboro.ac.uk

Abstract: Metal detecting is a popular hobby in England and Wales, and, since 1997, over 1.3 million finds have been recorded by the Portable Antiquities Scheme (PAS), a scheme to encourage the voluntary recording of artifacts found by the public. The metal detector can be a useful archaeological tool when used lawfully and responsibly; however, it is also a tool that is used for illicit purposes by individuals and groups wishing to obtain artifacts from archaeological sites on which they have no permission to detect. Information on the number and nature of incidents of illicit metal detecting, however, is difficult to collate owing both to the nature of the crime and to the way it is recorded (or not) by law enforcement authorities. In this article, we examine the strengths and limitations of the available official and unofficial sources on illicit metal detecting in England and Wales and explore the potential they have to tell us about current trends in this form of heritage crime. The first unofficial source is a list of incidents reported to Historic England, which contains basic information on 276 incidents recorded between 2010 and 2017. The second source is the result of a survey of the PAS's finds liaison officers regarding the extent to which they assisted law enforcement authorities for the years from 2015 to 2017. Both sources were then contrasted with a freedom of information request that was sent to all 49 police forces in the United Kingdom. Although there are some synergies between the unofficial and official sources, the lack of detail in any one dataset makes them of limited use in demonstrating trends in the macro- and micro-scales of time and place. 
Accordingly, many of the issues highlighted in this article could be resolved by devising a better system for police record keeping of metal detecting offences.

\section{INTRODUCTION}

Illicit metal detecting at archaeological sites is an international problem regardless of whether the state allows metal detecting or not. ${ }^{1}$ For example, recently we have seen an arrest at the UNESCO World Heritage of Haluza, Israel, for theft of Byzantine era coins; ${ }^{2}$ reports of illicit metal detecting at a US national park during the US government shutdown in early 2018; ${ }^{3}$ illegal excavations during 2017 in the Sukoharjo heritage site in Central Java; ${ }^{4}$ and reports of illegal digging in Kouklia village, Cyprus. ${ }^{5}$ The laws concerning metal detecting on archaeological sites vary from country to country, as do the ways in which law enforcement authorities record crimes arising from the illegal excavation and sale of antiquities. In England and Wales, where hobbyist metal detecting is popular and largely permissible (see the discussion below), the recording of "heritage crime" is yet to be

\footnotetext{
${ }^{1}$ In the context of this article, "illicit activity" is defined as any activity that is contrary to, or suspected of being contrary to, the law of the country in which it takes place, regardless of whether the activity has been prosecuted or not. It does not include activity that is unethical, irresponsible, or archaeologically destructive but that is lawful nonetheless.

${ }^{2}$ D. K. Eisenbud, “Man Arrested for Looting 150 Byzantine Era Coins from Archaeological Sites," Jerusalem Post, 29 January 2018, http://www.jpost.com/Israel-News/Man-arrested-for-looting-150-Byzantine-eracoins-from-archeological-sites-540133 (accessed 29 January 2018).

3 J. Eilperin, "While Yellowstone's Staff Was Furloughed, a Snowmobiler Got Way Too Close to Old Faithful," Washington Post, 22 January 2018, https://www.washingtonpost.com/news/energyenvironment/wp/2018/01/22/while-yellowstones-staff-was-furloughed-a-snowmobiler-got-way-too-closeto-old-faithful/?utm_term=.19e1c0c9cb3e (accessed 22 January 2018).

${ }^{4}$ G. Nugroho Adi, "Illegal Treasure Hunters Flock to Sukoharjo Heritage Site in Central Java," Jakarta Post, 1 November 2017, http://www.thejakartapost.com/news/2017/11/01/illegal-treasure-hunters-flock-tosukoharjo-heritage-site-in-central-java.html (accessed 30 January 2018).

${ }^{5}$ B. Browne, "State Must Step in to Stop Looting near Ancient Site, Kouklia Leader Says," Cyprus Mail Online, 2017, http://cyprus-mail.com/2017/12/05/state-must-step-stop-looting-near-ancient-site-kouklia-leadersays/ (accessed 30 January 2018).
} 
undertaken in a systematic and standardized way across police forces, ${ }^{6}$ although much progress toward this effort is being made. ${ }^{7}$

In spite of a variety of advances in tackling the problem of illicit metal detecting in recent years, it was still classed as a form of heritage crime for which there was "severely limited evidence" in a report published in $2012 .{ }^{8}$ Unlike many other forms of crime in the United Kingdom (UK) that are regularly recorded through victim surveys, such as the Crime Survey for England and Wales, the International Crime Victims Survey, or the Commercial Victimisation Survey, there is no such systematic coverage of illicit metal detecting. This lack of available data means that illicit metal detecting falls firmly into the so-called "dark figure of crime" - that is, crime that does not appear in official statistics and of which we have little formal knowledge. ${ }^{9}$ The lack of consistent official data available on illicit metal detecting means that we must turn to other, unofficial, sources to ascertain the potential trends in the nature and extent of illicit metal detecting. Yet, there has hitherto been no recent discussion of these unofficial sources, their limitations, and their relationship to the official records. This article aims to address these shortcomings.

In England and Wales, concern about damage to archaeological sites and the subsequent loss of knowledge through illicit metal detecting has been expressed ever since metal detectors became widely commercially available in the $1970 \mathrm{~s} .{ }^{10}$ The system of the legal protection of archaeological sites and artifacts in England and Wales is generally more relaxed when compared to other countries; metal detecting is lawful so long as permission has been granted by the landowner and so long as the land is not protected under one of the various land-based stewardship schemes ${ }^{11}$ or is designated as a "scheduled monument" (SM). The protection of archaeological sites largely circles around the secretary of state's discretion to designate sites of national importance under the

\footnotetext{
${ }^{6}$ Grove 2013.

${ }^{7}$ Heritage and Cultural Property Crime National Strategic Assessment 2017, https://www.nationalruralcrimenetwork.net/content/uploads/2017/11/Heritage-and-Cultural-PropertyCrime-National-Strategic-Assessment-2017-FINAL.pdf (accessed 27 May 2019) (Heritage and Cultural Property Assessment).

${ }^{8}$ Coombes et al. 2012, 9.

${ }^{9}$ Bidermann and Reiss Jr 1967; Skogan 1977.

${ }^{10}$ Oxford Archaeology 2009, 49; Thomas 2009, 2012; Wilson and Harrison 2013.

${ }^{11}$ Guidance for Landowners, Occupiers and Tenant Farmers in England and Wales, https://finds.org.uk/getinvolved/guides/guidancelandowners 27 May 2019) (Guidance for Landowners).
} 
Ancient Monuments and Archaeological Areas Act 1979-so-called SMs. ${ }^{12}$ There are around 20,000 entries on the list of SMs, though these are just a fraction of the total number of archaeological sites, most of which have no legal protection. ${ }^{13}$

The system of legal protection of archaeological artifacts is also restricted in its scope; archaeological finds are normally the property of the landowner or finder, depending on their agreement (though see discussion below), and there is no legal obligation to report finds other than those that fall under the Treasure Act 1996, though several forms of land use require finds to be reported, such as land under countryside stewardship schemes. ${ }^{14}$ The Treasure Act 1996 has effect in England, Wales, and Northern Ireland but only covers a restricted range of archaeological material. This includes any object other than a coin, provided that at least 10 percent by weight of metal is precious metal (gold or silver) and that it is at least 300 years old when found; two or more metallic objects of prehistoric date from the "same find" regardless of precious metal content; two or more gold or silver coins from the same find; 10 or more non-precious metal coins from the same find; and any object that would previously have been treasure trove. ${ }^{15}$ Finders of potential treasure have 14 days from the day of finding to report the object to the district coroner or 14 days from the first day the finder realizes the item is of potential treasure. Under the Treasure Act 1996, both the finder and the landowner are eligible for a reward (though caveats apply), and accredited museums have the opportunity to acquire items for public ownership. The practice of paying rewards to finders and landowners was thought to be a pragmatic way of encouraging reporting and reducing the illicit trade in antiquities. ${ }^{16}$

Complementing the launch of the Treasure Act 1996 was the establishment of the Portable Antiquities Scheme (PAS) in 1997, an initiative that continues today. ${ }^{17}$ The PAS is a pragmatic, though relaxed, response to the lack of protection for archaeological finds ${ }^{18}$ and has as its core aim to advance the knowledge of the history and archaeology of

\footnotetext{
12 1979, c. 46; Department for Culture, Media, and Sport (DCMS) 2013.

13 1996, c. 24; DCMS 2013.

${ }^{14}$ Oxford Archaeology 2009, 6; Lewis 2016a, 133.

15 DCMS, "Treasure Act 1996 Code of Practice," 1996

${ }^{16}$ Bland 2005.

17 Bland 2005; Lewis 2016a.

${ }^{18}$ Fincham 2008.
} 
England and Wales by encouraging the voluntary reporting of archaeological finds and preserving a digital record of each find. ${ }^{19}$ The scheme includes a network of 40 finds liaison officers (FLOs) covering England and Wales (though some only work part-time).

The PAS has, in conjunction with other stakeholders, sought to improve the standard of metal detecting by issuing a Code of Practice for Responsible Metal Detecting in England and Wales. ${ }^{20}$ Yet, while relationships with metal detectorists are largely positive and mutually beneficial, there are still many finders who choose not to record ${ }^{21}$ and still others who operate unlawfully. ${ }^{22}$ The existence of the PAS has not been able to stop the latter, not that it was primarily intended to, but it has been successful in providing information to law enforcement authorities, which is discussed later in this article.

\section{$<$ H1 $>$ EXISTING KNOWLEDGE OF THE PROBLEM}

Although the problem of illicit metal detecting was firmly in the sights of the archaeological community at the advent of the hobby of metal detecting, the first study on the extent and character of the problem only became available in 1995 following a systematic survey commissioned by English Heritage and undertaken by the Council for British Archaeology. ${ }^{23}$ The study was limited in its scope and only concerned legally protected monuments in England (known as SMs); nonetheless, it demonstrated that at least 188 SMs had been attacked over the period from 1988 to $1993 .{ }^{24}$ The study also noted that several monuments were being repeatedly attacked, that professional

\footnotetext{
${ }^{19}$ Bland 2005, 445.

${ }^{20}$ Code of Practice for Responsible Metal Detecting in England and Wales, 2017, https://finds.org.uk/getinvolved/guides/codeofpractice (accessed 27 May 2019) (Code of Practice). ${ }^{21}$ Barford 2010; Gill 2010; Hardy 2017. Estimating the number of finds that go unreported each year is exceptionally difficult, though there is broad agreement that it is not insignificant (see Daubney 2017). The most recent estimation is provided by Hardy (2017), who suggests that around 96 percent of recordable objects are not reported. This figure has been challenged by Deckers et al. 2018.

22 Daubney 2017, 792.

${ }^{23}$ Dobinson and Denison 1995.

${ }^{24}$ Dobinson and Denison 1995.
} 
archaeological excavations were also occasionally attacked, and that illicit metal detecting was very likely to be taking place on non-designated sites as well. ${ }^{25}$

In 2009, a second landmark study on illicit metal detecting was published. ${ }^{26}$ Known as the "Nighthawking Survey," ${ }^{27}$ this study provided baseline data on the extent and nature of the problem of illicit metal detecting affecting archaeological sites across England and Wales. Data was gathered from a wide range of sources including landowners and the PAS as well as through a public online survey. The survey collated information on 274 incidents affecting 240 sites spanning a 13 -year period. ${ }^{28}$ Owing to the nature of the data being sought by this survey, several of the conclusions rested on information that could not be validated, particularly where the evidence was anecdotal. Nonetheless, the survey was able to demonstrate broad trends in illicit metal detecting, notably that it was taking place right across the UK, including in areas not covered by the PAS. The survey also had the positive effect of raising awareness of illicit metal detecting and stimulating greater concern for the problem within the archaeological profession, within hobbyist groups, and also among local communities. The survey was also the stimulus behind several "heritage crime" initiatives in England and Wales. ${ }^{29}$ Responses included the publication of sentencing guidelines for heritage crime, ${ }^{30}$ greater cooperation between law enforcement agencies and heritage professionals, ${ }^{31}$ the formation of "heritage watch" schemes, ${ }^{32}$ and also the launch of Operation Chronos in 2015, a national partnership

\footnotetext{
${ }^{25}$ Dobinson and Denison 1995.

26 Oxford Archaeology 2009.

${ }^{27}$ The term "nighthawking" has been defined as the "illicit metal detecting on and removal of artefacts from archaeological sites." Wilson and Harrison 2013, 1. It is, however, a problematic term, not least because it implies that illicit activity is always undertaken at night, which is certainly not the case (Thomas 2010). The term "looting" - the meaning of which is generally dependent on context-is similarly problematic and is consequently not used in this article. Indeed, "looting" is an emotive term that could include both illegal activity and lawful but clandestine activity. For the purposes of this article, we prefer the term "illicit metal detecting."

${ }^{28}$ Oxford Archaeology 2009.

${ }^{29}$ Wilson and Harrison 2013, section 3; Thomas 2013.

${ }^{30}$ Historic England 2017.

${ }^{31}$ Wilson and Harrison 2013; Shelbourn 2014b.

32 National Rural Crime Network, “Hertfordshire Police Target Heritage Crime," 2017.

http://www.nationalruralcrimenetwork.net/best-practice/hertfordshire-police-target-heritage-crime/ (accessed 07 December 2017).
} 
campaign coordinated by the Essex police to combat illicit metal detecting. ${ }^{33}$ As a consequence, there has been an upturn in the number of arrests and successful prosecutions $^{34}$ and, naturally, media coverage of the issue. ${ }^{35}$

In spite of these successes, reliable information on the nature and extent of illicit metal detecting continues to be elusive. ${ }^{36}$ Part of the problem rests with restrictions that are understandably placed on public access to detailed information recorded on law enforcement databases. ${ }^{37}$ While requests can be made under the Freedom of Information Act 2000 , this only provides the public with high-level information. ${ }^{38} \mathrm{~A}$ major shortcoming of requests made under the Freedom of Information Act 2000, of course, is that it rests on the quality of the data being recorded; ${ }^{39}$ at present, there is no systematic way in which illicit metal detecting is recorded on police databases across the country. Some may include the keyword "looting," while others use the term "nighthawking" - a colloquial, though problematic, term often used to describe illicit metal detecting. ${ }^{40}$ Indeed, not all incidents involving illicit metal detecting will mention metal detectors at all, and some are recorded instead as theft or criminal damage, and, even in the former case, the data can often not be retrieved except via manual searches (of many thousands of police records).

\section{$<$ H1>METHODOLOGY}

For this research, we obtained alternative sources of data to examine illicit metal detecting. The previously unpublished data we present come from three separate sources, each with their own limitations and benefits. These are briefly outlined below. While official national statistics on the scale of illicit metal detecting in England and Wales are unlikely to be forthcoming any time soon, a list of all incidents brought to the attention of Mark Harrison (Head of Heritage Crime and Policing Advice, Historic England) has been

\footnotetext{
${ }^{33}$ Essex Police, n.d. Operation Chronos. https://www.essex.police.uk/getmedia/8d6ac7f8-8de4-4b3b-a42438491f486381/op_chronos.pdf (accessed 22 February 2018).

${ }^{34}$ Wilson and Harrison 2013.

${ }^{35}$ See Shelbourn (2014a) for a discussion on the public response to such media coverage.

${ }^{36}$ Grove 2013, 243-47.

${ }^{37}$ Coombes 2012, 15.

382000 , c. 36.

39 Johnson and Hampson 2015.

40 Oxford Archaeology 2009, 1.
} 
maintained since 2010. The list was begun when Harrison was seconded as policing advisor to English Heritage (now Historic England), and it implements one of the recommendations from the Nighthawking Survey. ${ }^{41}$ The Historic England list (HE list) contains information on 276 incidents, in addition to several cases of antiquities trafficking. The majority of entries on the list relate to those identified as part of the aforementioned Operation Chronos. The list provides an overview of when and where incidents took place and, in some cases, the outcome of the incidents. The content may in part be reflective of policing practices and engagement with Operation Chronos as much as it is a reflection of illicit activity. Nonetheless, the list allows us to gain what is perhaps the most comprehensive overview of illicit metal detecting in England and Wales.

The second source of data on illicit metal detecting presented in this article is the annual Survey of Finds Liaison Officers (FLO survey), which was undertaken by Adam Daubney, one of the authors of this article. This survey collated data on the extent to which the PAS's FLOs assisted law enforcement agencies from 2015 to $2017 .{ }^{42}$ The PAS operates through a network of FLOs who are spread out across England and Wales and who work directly with the public in recording each find that is made. Naturally, the majority of individuals recording their finds are metal detector users. ${ }^{43}$ This involvement with the metal detecting community often leads to FLOs being the recipients of third party information on illicit metal detecting, in addition to being a useful source for specialist knowledge. Accordingly, FLOs frequently have contact with law enforcement authorities, either in reporting potential illicit activity and/or providing advice and specialist assistance.

The third and final source of data was a freedom-of-information request that was sent to all 49 police forces in the United Kingdom, including non-geographic forces such as the British Transport Police. Police record crimes that are reported to them under the relevant crime codes. Illicit metal detecting does not have a separately allocated crime code (nor does heritage crime); accordingly, incidents fall under a range of different records depending on the police force-for example, theft, attempted theft, or trespass. Police databases also have free text fields where details on the modus operandi or other

\footnotetext{
${ }^{41}$ Oxford Archaeology 2009, 109.

42 Daubney 2017.

${ }^{43}$ Lewis 2016b, 4.
} 
details of the crime may be recorded. It was requested that searches be undertaken to identify relevant records for the period $2015-17$ based on a number of suggested keywords. Thirty-nine freedom-of-information (FOI) responses were returned within the statutory 20 working days, of which 18 requests were refused on the grounds that the searches would exceed the allowable time (18 hours in England) and financial commitment ( $£ 450$ in England) under the Freedom of Information Act 2000.

These three different sets of statistical data give us new insights into the problem of illicit metal detecting in the UK. We have drawn together data from the appropriate sources to examine (as far as possible) five key areas: the overall number of incidents identified from the data; the designation of sites known to be targeted by illicit metal detecting; the distribution of known incidents; the character of the sites identified within the datasets; and the time of year of the incidents.

\section{$<$ H1 $>$ RESULTS}

\section{$<H 2>$ Number of Incidents}

We turn first to the numbers of known incidents of illicit metal detecting in England and Wales. ${ }^{44}$ The HE list, the FLO survey, and FOI responses give us different elements of the picture, with the first providing us with numbers that have come to the attention of Historic England, the second the number of law enforcement cases involving illicit metal detecting with which FLOs have been engaged, and the third giving us the (incomplete) numbers that the police could extract from their databases. One of the conclusions of the Nighthawking Survey was that illicit metal detecting has increased slowly since 1995 . The survey found a gradual increase in incidents between 1995 and 2006, with a dramatic increase for 2007; this increase was thought to be a result of the data collection rather than an actual increase of incidents. ${ }^{45}$

The HE list demonstrates that knowledge of illicit metal detecting has increased over the period 2010-17, though at a greater level than previously known (Figure 1). This is demonstrated by two statistics: first, the HE list contains information on 276 incidents

\footnotetext{
${ }^{44} \mathrm{An}$ "incident" is any report of suspected illicit activity.

45 Oxford Archaeology 2009, 44.
} 
over a seven-year period, while, in contrast, the Nighthawking Survey contains information on 274 incidents over a 13-year period.

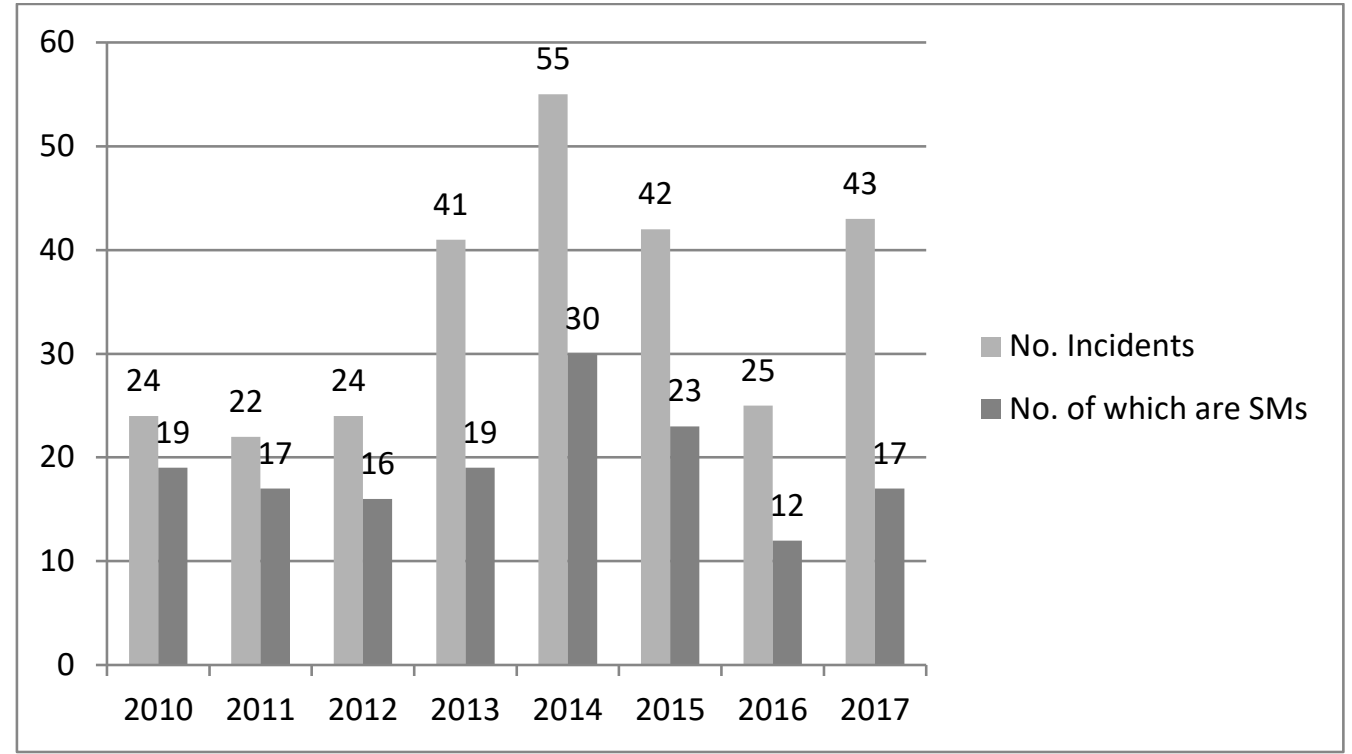

Figure 1. Illicit metal detecting on SMs and non-designated sites by year (HE list).

However, we should be cautious about the extent of incidents and trends identified via the HE list as this does not necessarily represent the true extent of illicit metal detecting over this time period; the true figures are likely to be much higher as many attempts and successful illicit metal detecting events are likely to go unnoticed due to the remote/rural locations of many suitable sites. ${ }^{46}$ Yet the differing methodology between the previous survey and this dataset mean that they are not directly comparable. Indeed, both datasets are of limited use given that an "incident" is simply a report of illicit activity rather than a conviction of illicit activity.

That said, we have a second observation; although there is a two-year gap in knowledge between the end of the Nighthawking Survey data (2008) and the beginning of the HE list (2010), the number of incidents recorded in 2010 was more than twice that in $2008 .{ }^{47}$ Notably, this figure has now doubled from just over 20 incidents in 2010 to just over 40 in 2017 (Figure 1). Again, whilst this should be treated with caution due to the differing methodologies of the two sources, this is a dramatic difference and suggests at the very least a greater policing of the problem of illicit metal detecting.

\footnotetext{
${ }^{46}$ See Grove, Daubney and Booth 2018, for a discussion of the characteristics of sites that may be targeted.

${ }^{47}$ Oxford Archaeology 2009, 45, figure 10.
} 
Although the general trend is one of greater numbers of recorded incidents, the HE list recorded a decline in 2016 when just 25 incidents were noted. This may well be artificially low; indeed, the survey of FLOs noted that staff were involved in 27 cases in 2016 and, collectively, had information on at least 60 further alleged incidents. ${ }^{48}$ While some of the cases on the HE list rest on anecdotal evidence provided by FLOs and others, the majority of incidents are those that came to the attention of the police. It is likely that some, but not all, of the incidents identified by FLOs in the survey (Figure 2) are a subset of those shown in Figure 1. The data does not allow for a direct comparison.

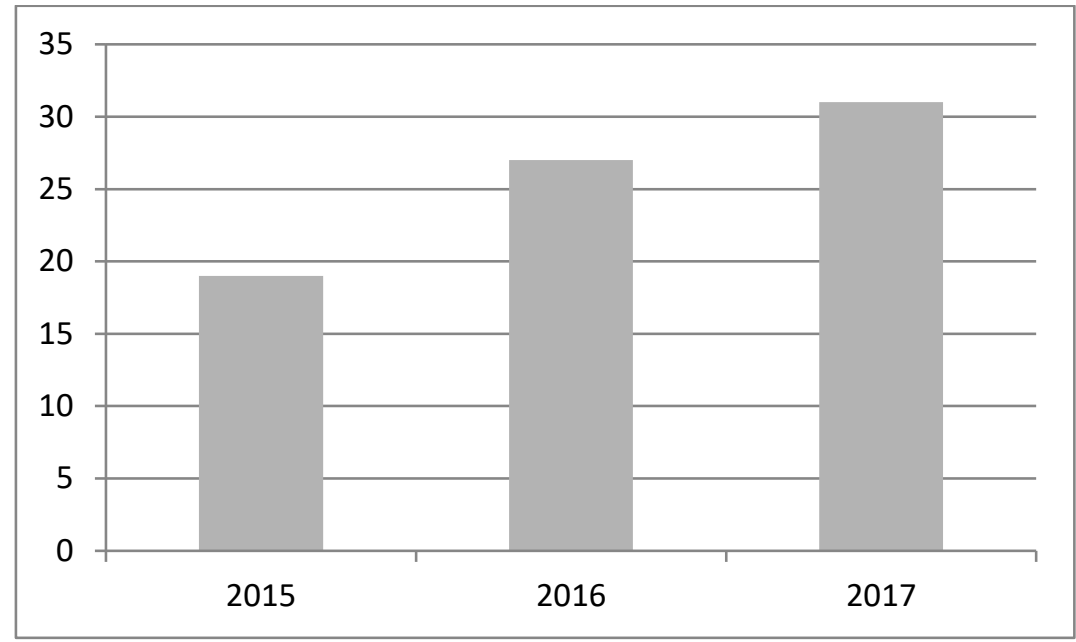

Figure 2. Number of incidents per year where FLOs assisted law enforcement authorities (FLO survey).

The overall trend noted by the FLO survey is one of increasing involvement with law enforcement authorities, ${ }^{49}$ with 19 cases in 2015, 27 in 2016, and 31 in 2017 (Figure 2). The types of incidents that FLOs advised on during the period 2015-17 were dominated by reports of illicit metal detecting, closely followed by reports of items that potentially qualify under the Treasure Act 1996 but which had not been reported to the coroner (Figure 3). FLOs also assisted law enforcement authorities with their enquiries into the illicit sale of potential treasure and, less commonly, of archaeological material that does not fall under the auspices of the Treasure Act 1996. Unfortunately, the data is such that it is not possible to cross-reference individual cases with the HE list, but there is

\footnotetext{
48 Daubney 2017, 793.

${ }^{49}$ There were 15 responses for 2015, 30 responses for 2016, and 28 responses for 2017.
} 
likely to be considerable overlap given the close working relationship that FLOs have with Mark Harrison and Operation Chronos.

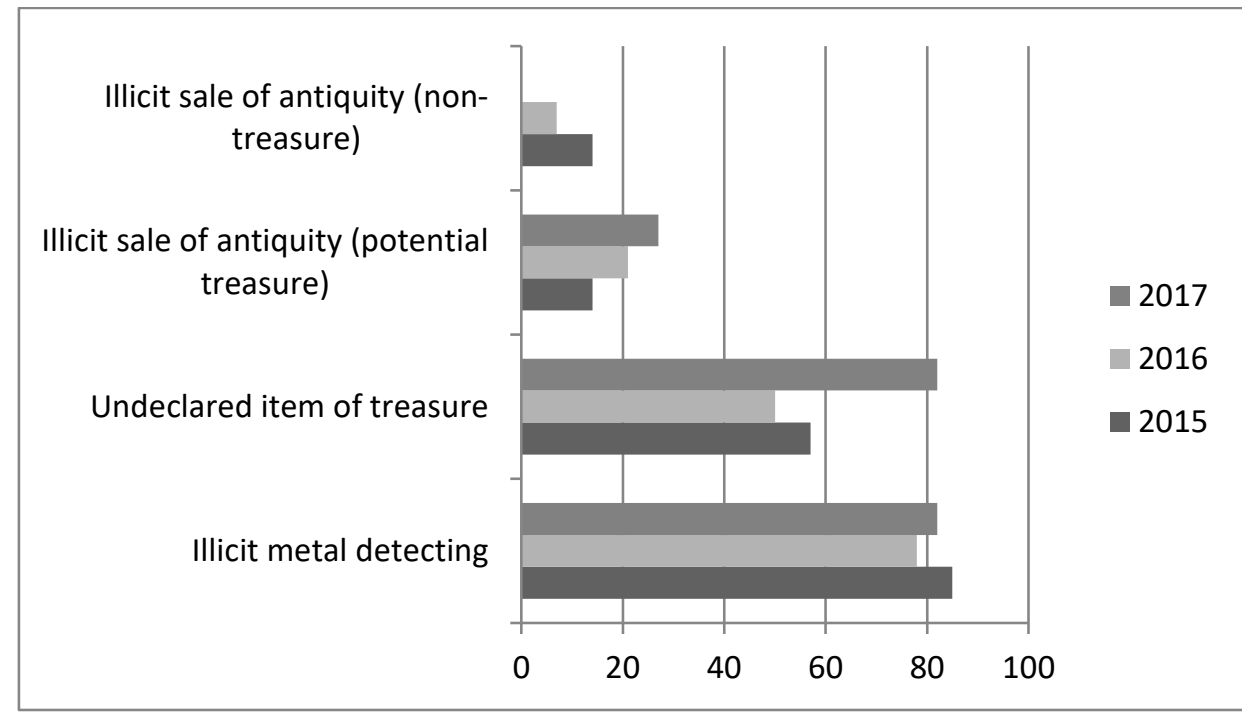

Figure 3. Types of incidents that FLOs advised on during the period 2015-17 (FLO survey).

A similar problem of cross-referencing cases occurs when we examine the scarce data provided in response to the FOI requests. In total, 48 cases of illicit metal detecting were highlighted in response to the request. However, after examining the detail provided, a number of these responses were irrelevant, including knife crime and cable theft. This left us with an estimated 44 recorded illicit metal detecting crimes. Of these, 29 were identified within just three police forces: Lincolnshire, Norfolk, and Suffolk. There is clearly much difficulty with identifying relevant cases: 18 of the 39 responding police forces refused the FOI request on the basis that manual searches would have to be conducted of the tens of thousands of records (in most cases) to identify cases of illicit metal detecting. Those forces that were able to provide data were careful to caveat their response with the limitations of the data searches they were able to conduct. The method of searching also varied by police force area, meaning that the numbers of incidents are not reliable nor directly comparable-either to other forces or to the other sources of data we discuss herein. For example, the FOI response from the Northumbria Police contains information on one incident, though the HE list contains information on eight incidents. The incident recorded on the FOI response occurred in September 2017; however, in 2015, the Northumbria Police issued a joint press release about incidents 
occurring on scheduled ancient monuments along Hadrian's Wall. ${ }^{50}$ These incidents were not caught in the FOI trawl.

Similar instances of "missing data" were also noted in the FOI responses for other police force areas. The FOI response from the West Midlands Police returned no incidents for illicit metal detecting, but it did include one incident of metal theft (presumably theft of lead from a church roof). However, the HE list contains 18 incidents of illicit metal detecting for this region. Two of the 18 incidents of illicit metal detecting listed on the HE list are accompanied by crime numbers; nonetheless, neither was caught by the FOI search. The joint FOI response issued by the Norfolk and Suffolk Police includes information on 20 incidents of illicit metal detecting and is by far the most comprehensively recorded response in comparison to the other police forces. The large number of incidents is also reflected in the 33 incidents recorded on the HE list. On face value, there appears to be much overlap between the Norfolk/Suffolk response and the HE list, though it is difficult to be absolutely sure in most cases.

The FOI response exercise demonstrates that there is much variation in the way that heritage crime, particularly with regard to illicit metal detecting, is recorded (or not, as the case may be). Indeed, "known" incidents on the HE list, which contains crime reference numbers, sometimes do not appear on FOI responses even though they do appear on the HE list. The HE list therefore arguably gives the most reliable picture of illicit metal detecting across England, though the survey of FLOs suggests that the occurrence of incidents might be somewhat greater.

The FLO survey also captured information on the type of assistance offered to law enforcement authorities using the following categories: (1) reporting first-hand information; (2) reporting third party information; (3) advising on policy/legislation; (4) advising on whom to contact; and (5) appearing in court as an expert witness (Figure 4). Broadly, the statistics for each year compare well with one another and show that FLOs contact law enforcement authorities with both first and third party information. FLOs were also instrumental in advising on policy and legislation surrounding archaeological antiquities and sites; these include the Treasure Act 1996, the Ancient Monuments and

\footnotetext{
50 Press Association, “Police Issue Warning over Hadrian's Wall Nighthawking," The Guardian, 11 February 2015, https://www.theguardian.com/uk-news/2015/feb/11/police-warning-hadrians-wall-nighthawking (accessed 22 February 2018).
} 
Archaeological Areas Act 1979, the Dealing in Cultural Objects (Offences) Act 2003, and the legislation regarding export licenses. ${ }^{51}$ It might be notable that there was a decline in the proportion of incidents in which FLOs advised on whom to contact, which probably reflects both the greater awareness of the issue of illicit metal detecting and the greater networking between agencies that has arisen from Operation Chronos and the efforts of Historic England and others. ${ }^{52}$

A decline in the proportion of occasions where FLOs reported first-hand information was also noted over the period, though third party information remained consistent. This statistic is difficult to interpret, but it does stress the important role that responsible metal detectorists have in reporting potentially illicit activity.

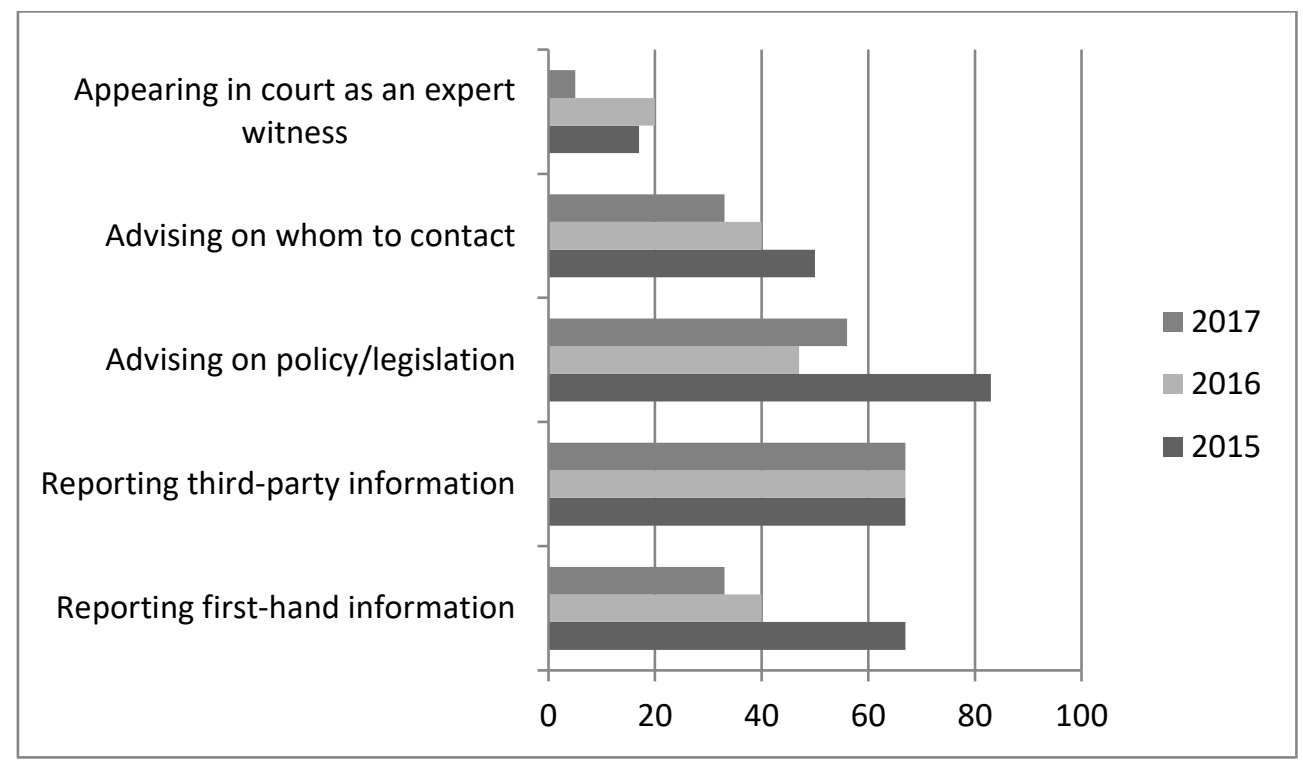

Figure 4. Capacities in which FLOs assisted law enforcement authorities. Figure shows the percentage of incidents (FLO survey).

\section{$<$ H2>Illicit Activity at Legally Protected and Non-Protected Sites}

The HE list provides information on the designation of the site that has been attackedthat is, whether the site is legally protected or not. We have previously commented that SMs under cultivation may be perceived by illicit metal detectorists to be prime targets, in part owing to their status as SMs and also because of the information and publicity about

\footnotetext{
512003 , c. 27.

52 Wilson and Harrison 2013.
} 
a particular SM that often is found online. ${ }^{53}$ The number of incidents recorded on the HE list that affected SMs is significant: 151 incidents reported across 121 designated sites. The numbers range from between 12 and 30 incidents, giving an average of 15 incidents per year over the period. By way of comparison, the Nighthawking Survey, which covers the period 1995-2008, identified 88 SMs that had been attacked. ${ }^{54}$ This latter statistic, however, was thought to be an underestimate of the problem. ${ }^{55}$ Indeed, it is much lower than the findings of a survey published by the Council for British Archaeology in 1995, which identified 188 SMs attacked between 1989 and 1993. ${ }^{56}$

The HE list demonstrates that non-designated sites were also frequently targeted - indeed, slightly more so than SMs. The number of reported incidents of illicit metal detecting on non-designated sites between 2010 and 2017 is somewhat variable, but there is an overall increase. The dramatic rise seen after 2013 might be partly attributable to the greater liaison between $\mathrm{HE}$ and the stakeholders, which naturally resulted in an increase in the reporting of both incidents and intelligence for nondesignated sites. Post-2013 statistics, therefore, do appear to give a more reliable view of the situation in England and Wales, with the levels of reporting being approximately more than 40 cases per year. Overall, the HE list indicates that the number of incidents affecting SMs is rather constant, while incidents affecting non-designated sites is increasing.

Accordingly, it might well be the case that SMs are increasingly not seen as the beacons as they once were; 20 years of recording by the PAS has demonstrated that the rural landscape contains many more sites than were previously known. ${ }^{57}$ These "new" and non-designated sites may now be perceived as more fruitful targets. It may also be the case that a greater awareness of the law has resulted in areas adjacent to SMs being targeted rather than the protected site itself. ${ }^{58}$

The HE list indicates that of the total number of incidents recorded each year, around 40-48 percent will affect a SM. Naturally, this statistic should be of interest to any

\footnotetext{
53 See also Grove, Daubney, and Booth 2018.

54 Oxford Archaeology 2009, 36.

55 Oxford Archaeology 2009, 89.

${ }^{56}$ Dobinson and Denison 1995; Oxford Archaeology 2009, 70.

57 Brindle 2014, 14; Daubney 2016, 98-100.

${ }^{58}$ See, e.g., "Facing Jail for My Hobby," Shields Gazette , 16 December 2004, https://www.shieldsgazette. com/news/facing-jail-for-my-hobby-1-1267789/amp (accessed 26 November 2017).
} 
police officer who apprehends an individual on or leaving an archaeological site; there is a good chance that if the individual has committed theft, there will also be offences under the 1997 Archaeological Areas and Ancient Monuments Act. Indeed, SMs make up a very small proportion of the total archaeological resource, perhaps as little as 2-4 percent. Even with biases in reporting, SMs still appear to receive a disproportionate amount of attention from illicit metal detecting.

\section{Distribution}

The distribution of the 276 incidents recorded on the HE list demonstrates the same spatial trend in offences that was noted by the Nighthawking Survey-that is, there is a general background level of illicit metal detecting across the country. We can view general trends in the reporting and recording of illicit activity in more nuanced ways by classifying data according to the geographical regions defined by Historic England. These regions are useful on two accounts: first, they divide the country according to broad landscape types and, second, they make it easier for Historic England to tailor historic environment advocacy to a particular area. ${ }^{59}$ Classifying illicit activity by these regions reveals greater (reported) activity occurring in the South Eastern and Eastern counties of England, with relatively large numbers of incidents also noted in the South West and East Midlands (Figures 5 and 6). ${ }^{60}$ These "prime" regions, of course, do contain large areas of land under arable cultivation-conditions that make sites more vulnerable to illicit metal detecting owing to the ease of recovering artifacts. ${ }^{61}$

\footnotetext{
${ }^{59}$ Historic England, "Regional Reports," https://historicengland.org.uk/research/heritage-counts/regions/ (accessed 27 May 2019).

${ }^{60}$ Oxford Archaeology 2009, 40, figures 7-8.

${ }^{61}$ Grove, Daubney, and Booth 2018.
} 


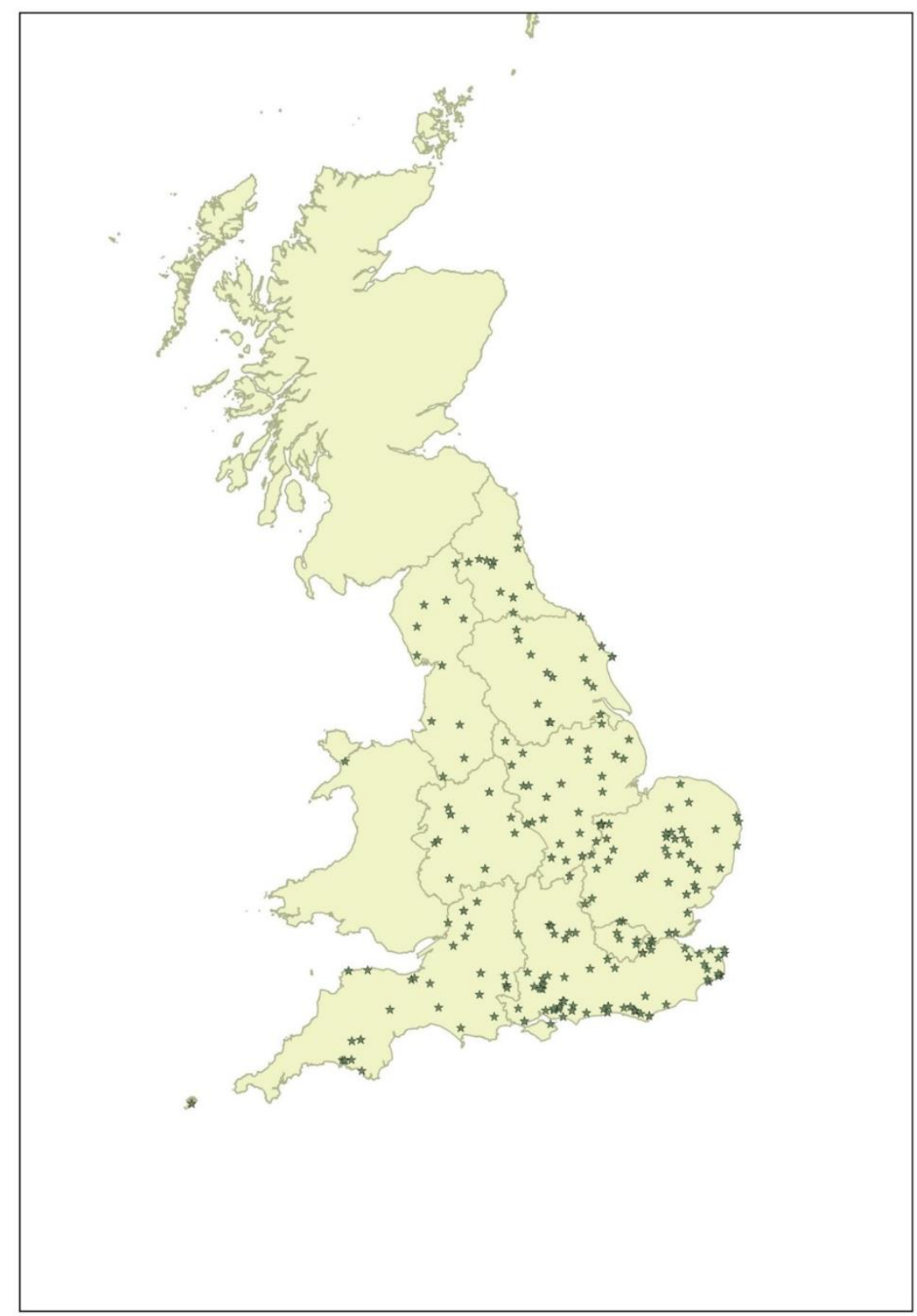

Figure 5. Incidents in England and Wales 2010-17 (HE list). Note that data from Scotland are not included. 


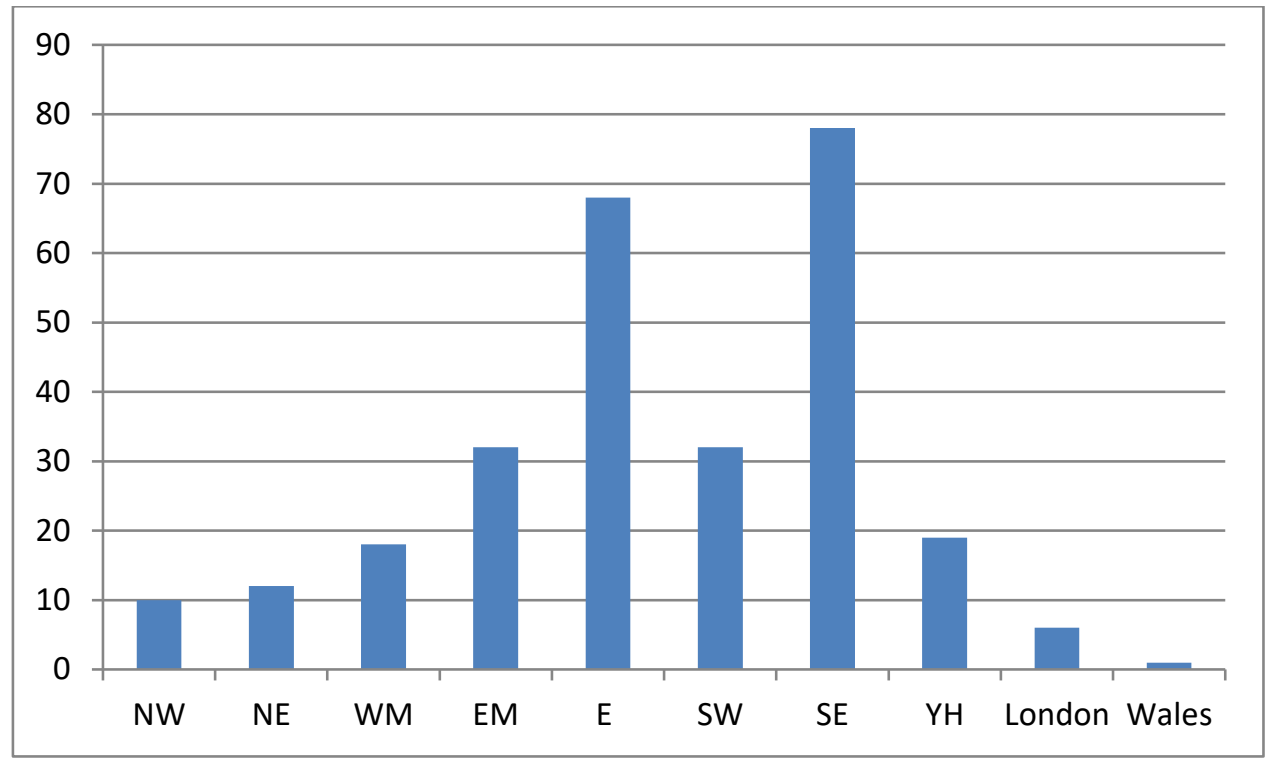

Figure 6. Distribution of incidents by region (HE list).

The incidents identified from the HE list are expressed more clearly when the HE list is viewed by county, with the highest reported incidents occurring in Hampshire, Kent, Suffolk, Norfolk, Cambridgeshire, Essex, and North Yorkshire respectively (Figure 7). Yet a degree of caution needs to be exercised when interpreting county statistics; the dramatic rise in incidents in Hampshire when compared with the Nighthawking Survey is an anomaly but is one that can be explained by the recent efforts of the Police Country Watch Team to increase reporting. ${ }^{62}$ Indeed, there is a broad correlation between hot spots and those areas where a greater degree of police engagement has taken place. As with all crime statistics, these data are sensitive to a range of nuances, not least local policing initiatives.

${ }^{62}$ Oxford Archaeology 2009, 43, figure 8; Harrison, personal communication June 2018. 


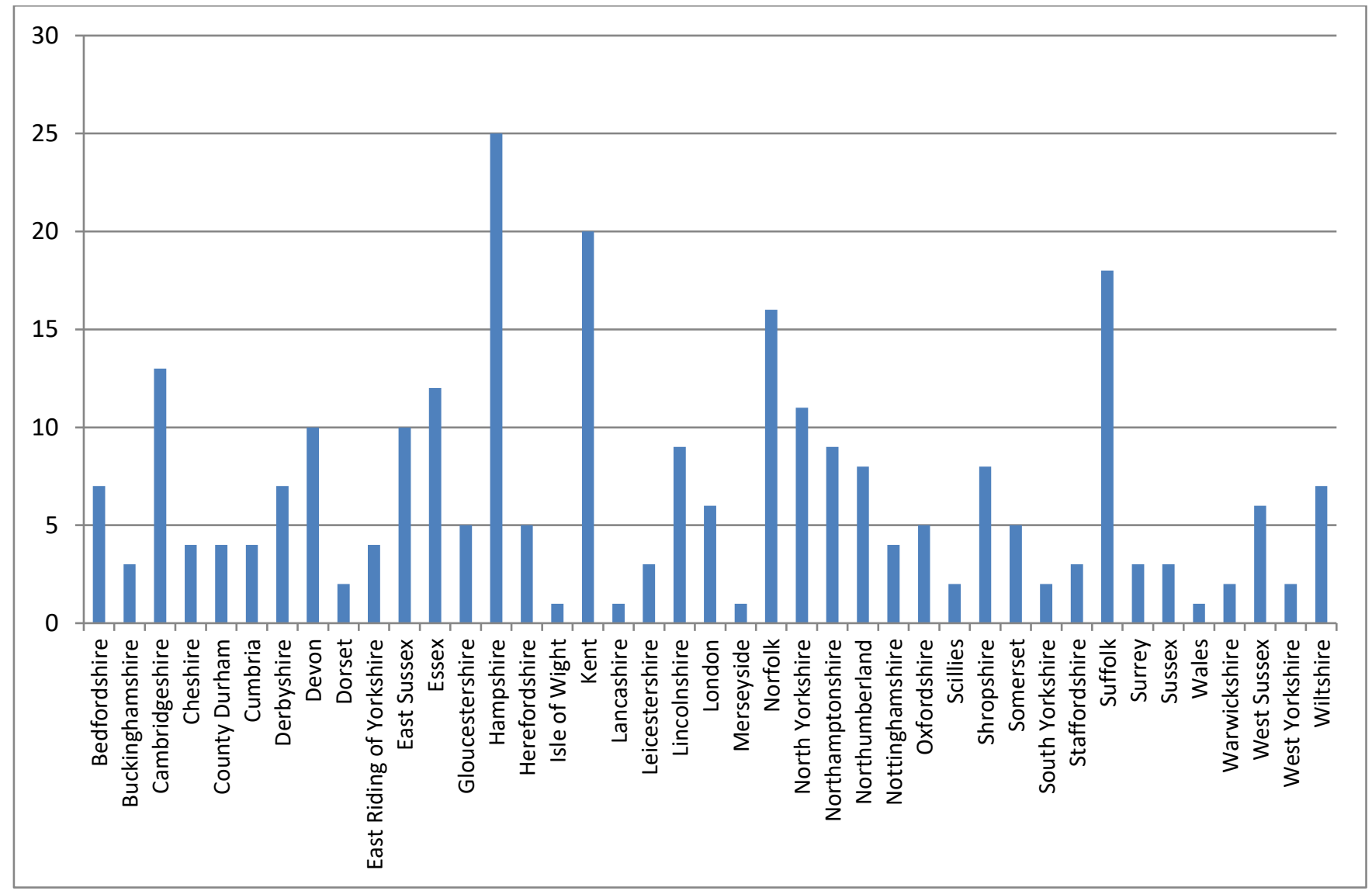

Figure 7. Distribution of incidents by county (HE list).

It is not surprising that we see clusters of illegal metal detecting in certain counties, such as Hampshire, Kent, Norfolk, and Suffolk. We know that once a place is targeted by offenders on one occasion, it is far more likely to be targeted again. This is known as repeat victimization, and it is observed across all crime types (with the notable exception of murder, which even then is often preceded by a number of attempts or violent offences). The reasons for this are usually a combination of state heterogeneity and event dependence factors. In this case, an area may be particularly targeted because of features that make it attractive for illicit metal detecting: first, a rural, remote area with many sites that may be perceived as having potential for a relatively high return on effort (state heterogeneity) or, second, an offender who has successfully retrieved artifacts from the ground who may return to the area to identify further items (event dependence). We also 
see a proportion of individual sites being repeatedly targeted according to the HE list, with an average of 1.25 incidents per site. ${ }^{63}$

There are other reasons that we may see a clustering of reports that bear no relation to the actual incidence of illicit metal detecting. Landowners, visitors, residents, and caretakers in some areas may be more aware of abnormal behavior in an area and, thus, more likely to report their observations. There may be greater membership in schemes such as Heritage Watch, which formalize awareness and encourage reporting. There may be police officers or volunteers with a particular interest in heritage or archaeology, resulting in a greater likelihood of reports being forwarded for inclusion in the HE list. Regardless, it is likely that the incidents identified are an understatement of the problem, and we may also see a greater concentration of crime events with increased reporting.

\section{$<H 2>$ Character of Site}

The HE list can also be interrogated for information regarding the character of the sitethat is, what period it belongs to and what "type" of site it is (for example, castle, fort, temple, farmstead). Naturally, these broad categories must be treated with due caution; many archaeological sites were used over long periods of time and cannot be assigned to any one particular period. Likewise, the nature of a site may have changed over time; land that was used as a farmstead in the Roman period may be a cemetery in the Anglo-Saxon period, for instance. These complexities aside, the HE list can be gleaned for broad trends.

Regarding the period of site, when examined on a national level, there is a clear trend toward incidents occurring on Roman and medieval sites. In fact, this is a trend that was established by both the Council for British Archaeology survey ${ }^{64}$ and the Nighthawking Survey. ${ }^{65}$ However, it is difficult to know whether illicit metal detectorists specifically target Roman and medieval sites or whether it is a bias resulting from sites of these

\footnotetext{
${ }^{63}$ For a more in-depth consideration of identifying the risk of illicit metal detecting at archaeological sites, see Grove, Daubney, and Booth 2018.

${ }^{64}$ Dobinson and Denison 1995.

${ }^{65}$ Oxford Archaeology 2009, 44, figure 9.
} 
periods being more common. ${ }^{66}$ Closer analysis of incidents within these two archaeological periods reveals the general nature of the sites being attacked. In total, 64 percent of incidents on Roman sites involved settlements (42 incidents), while 23 percent of incidents occurred on forts, many of which are SMs (15 incidents). Damage to sites of medieval date concentrated on castles (17 incidents [40 percent] of sites within the period), and abbeys or priories (19 incidents [45 percent] of sites within the period). Again, the majority of these being SMs.

A slight increase in attacks on Iron Age sites is notable in the HE list; incidents were recorded on 21 hill forts, all of which are SMs. Curiously, a number of prehistoric stone circles were also targeted in spite of these being sites that predate the introduction of metalwork. In these instances, it might be that illicit metal detectorists with a poor understanding of archaeology are simply drawn to sites because of their perceived status. $^{67}$

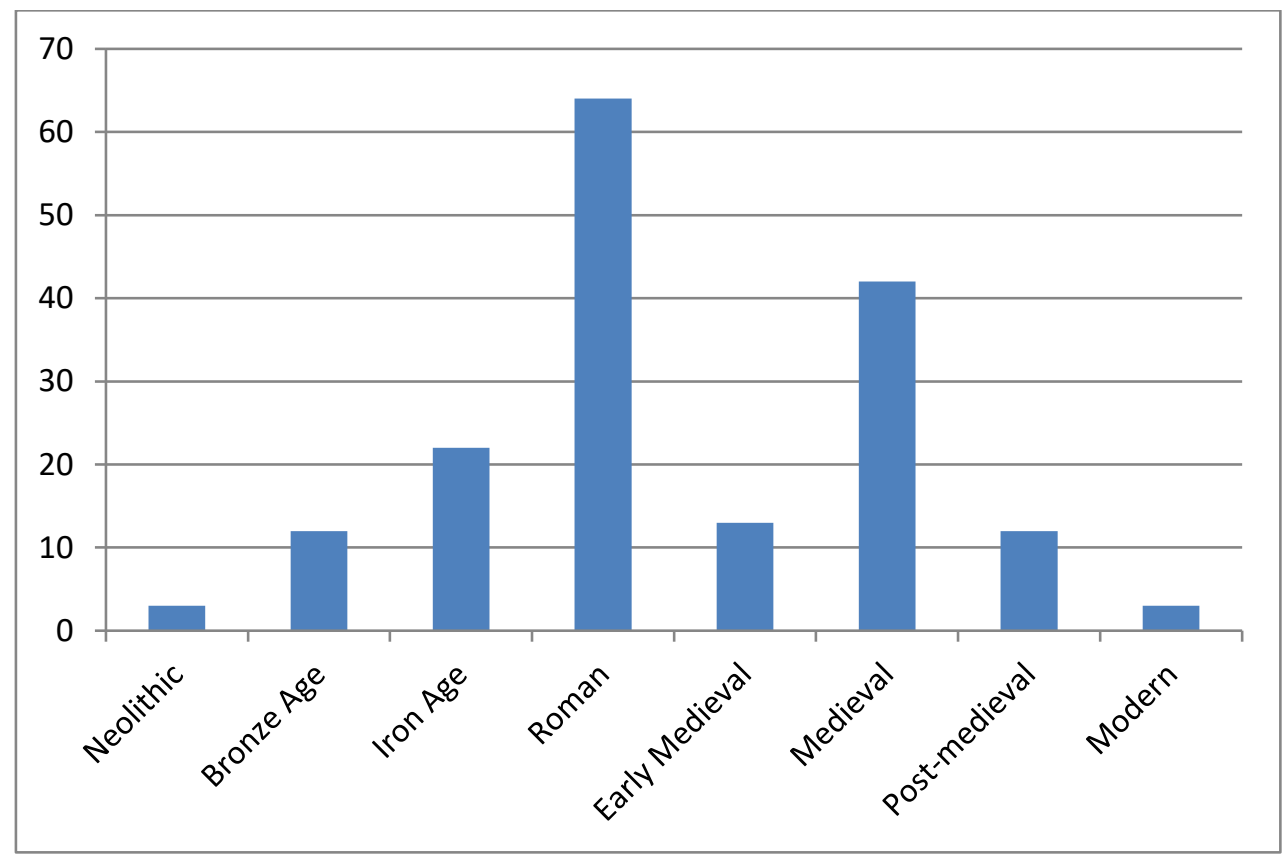

Figure 8. Period to which site is dated (HE list).

\footnotetext{
${ }^{66}$ E.g., Daubney 2016, 98-101; Oxford Archaeology 2009, 44, figure 9.

${ }^{67}$ Grove, Daubney, and Booth 2018.
} 


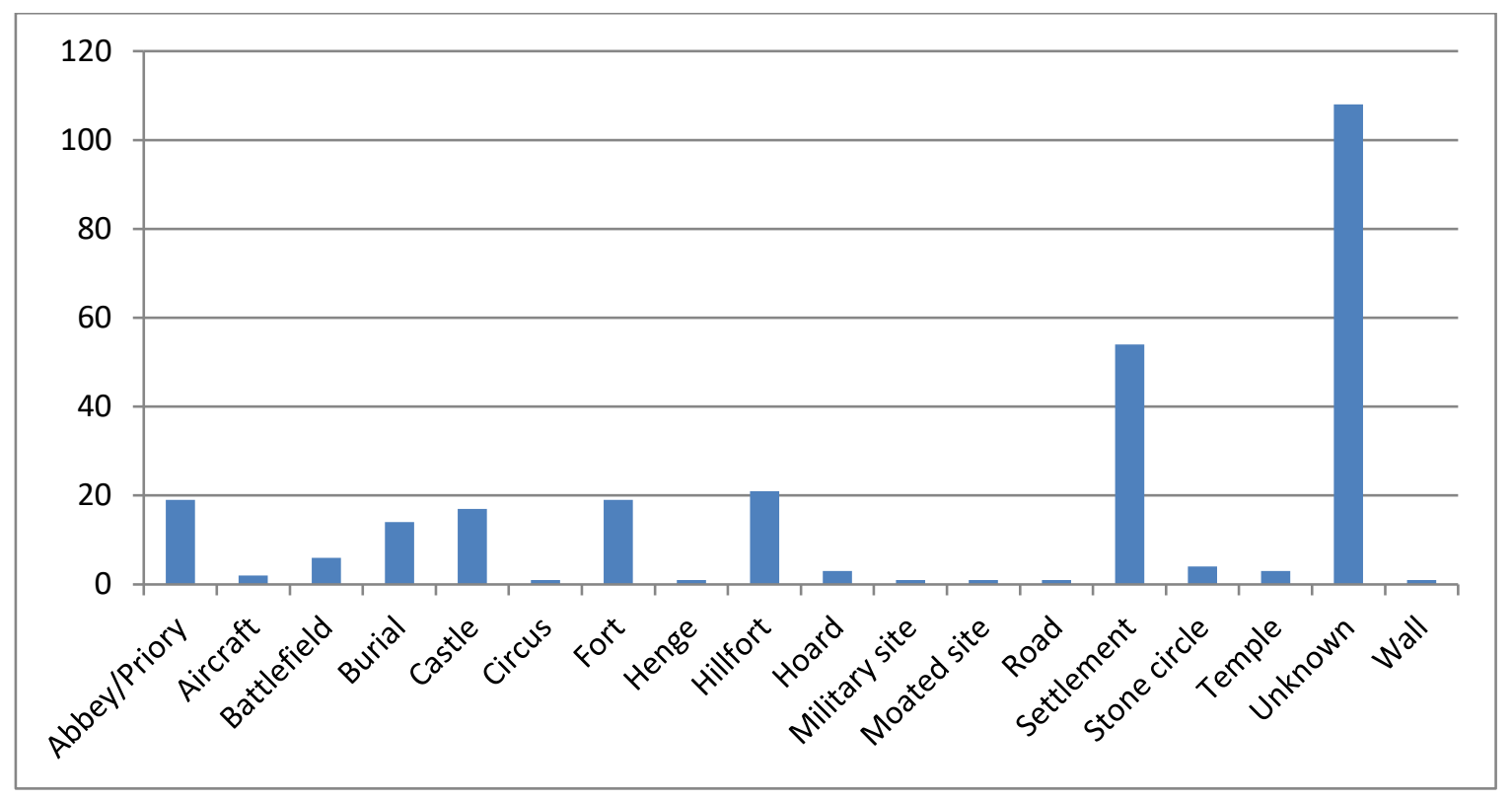

Figure 9. General type of site (HE list).

\section{$<$ H2 $>$ Time of Year}

As well as giving us an annual overview of illicit metal detecting, the HE list also records the month in which incidents took place (Figure 10). Incidents of illicit metal detecting were reported fairly evenly across the agricultural year, though there was a notable reduction during June and July probably owing to the height of crops reducing access to arable land. The rise in August may be associated with crop harvesting, which results in large areas of land becoming accessible once again. Far fewer incidents were reported for September, however. The reasons for this are difficult to ascertain, but it could be due to fields being rough plowed after harvest in preparation for the next crop. Rough plowing creates deep furrows that make metal detecting very difficult.

The high level of incidents experienced in the summer months was also a feature noted by the Nighthawking Survey, but the reduction in incidents in July and September revealed by the HE list is a trend that was masked in the Nighthawking Survey, in which incidents were grouped according to season (for example, "summer"). ${ }^{68}$

\footnotetext{
${ }^{68}$ Oxford Archaeology 2009, 46, figure 11.
} 


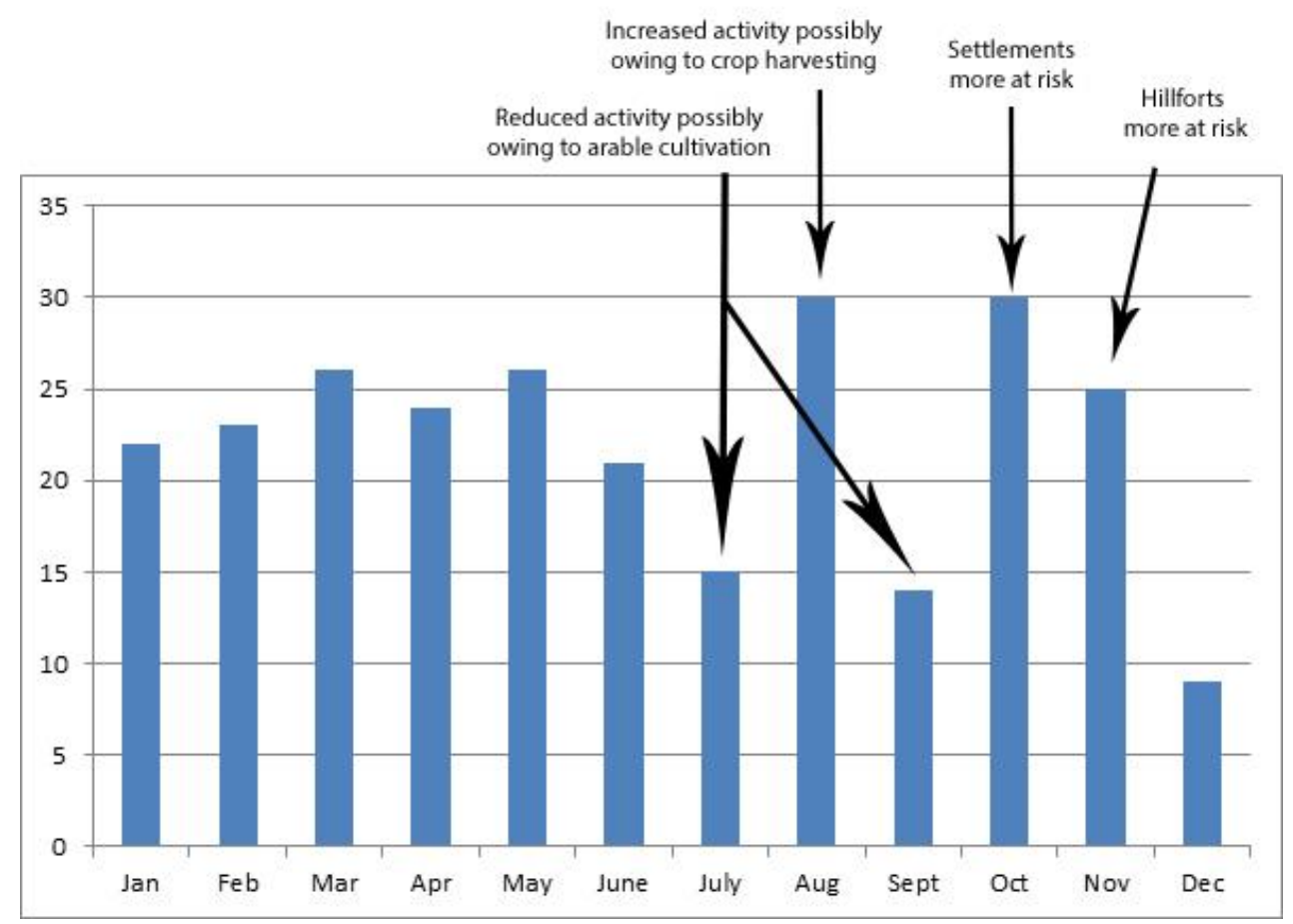

Figure 10. Number of incidents in $2010-17$ by month (HE list).

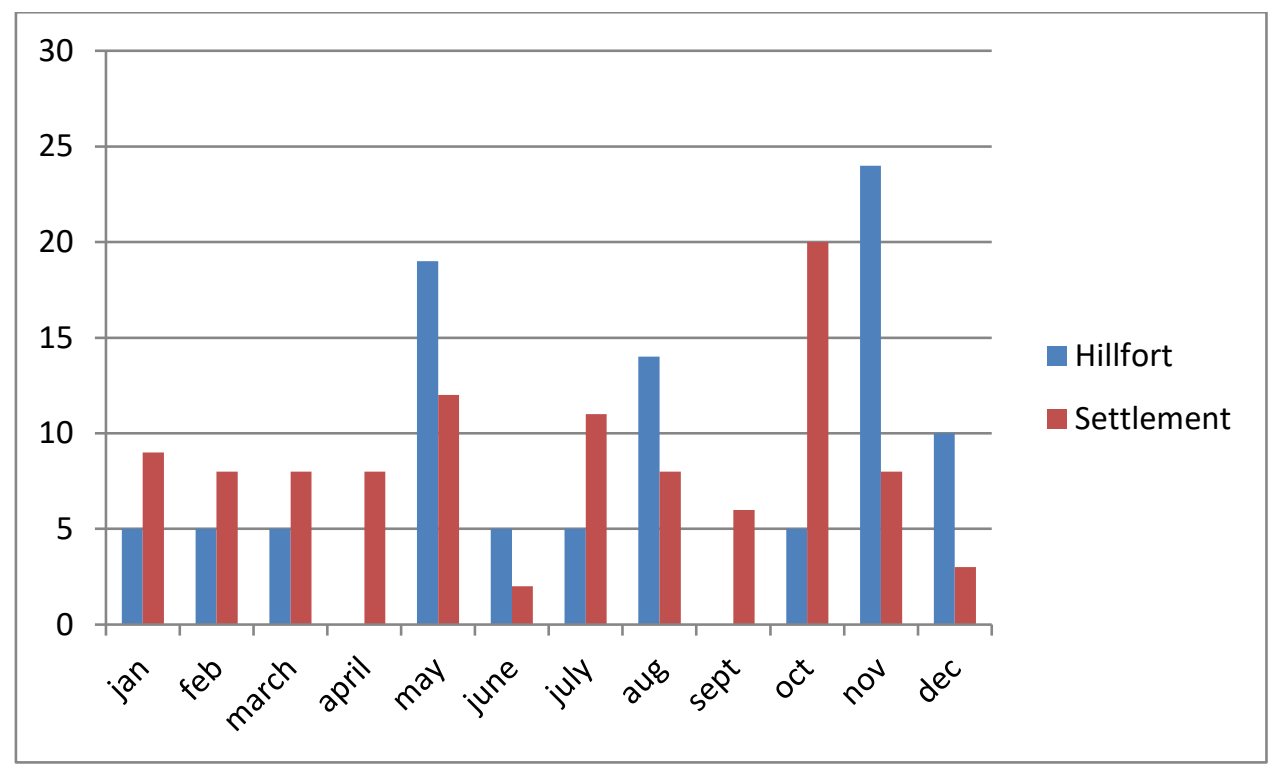

Figure 11. Proportion of incidents of illicit metal detecting per month on Iron Age hill forts and multi-period settlements (HE list).

Of course, by grouping all of the incidents of illicit metal detecting together by month we inevitably mask trends on finer scales of time and place. Perhaps the most visible of these trends emerges when we explore the relationship between land use and site type-in this instance, Iron Age hill forts and multi-period settlements. The majority of Iron Age hill forts in England comprised large areas enclosed by multiple ditches and 
banks. Owing to the grand scale on which most were constructed, many survive today as earthworks. Those that are protected are often set to permanent pasture and are therefore more accessible throughout the year. This is in contrast to settlements, which for the most part are undesignated and under cultivation. The strong association between settlements and modern arable cultivation, however, does mean that they are only accessible during the months when there are no crops on the field or when the crops are still very young. These differing cycles of access, of course, do have implications for their risk from illicit metal detecting.

We can see traces of this trend within Figure 11, which shows the percentage of incidents affecting hill forts and settlements. For both types of sites, there are peaks in May, August, and November, broadly complementing the national picture. However, there are no, or few, incidents on hill forts during September and October-months for which there are incidents on settlements, notably so in October. The situation flips for November, where hill forts see a dramatic upsurge in detecting activities, while settlements see a dramatic decline. This might indicate that the same individuals are targeting both types of site, but are diverting their attention according to what is immediately favorable; illicit metal detectorists target fields containing ancient settlements when they are freshly rolled and then divert their attention to hill forts when the nights get longer and arable fields become less accessible. Of course, these are (over)generalizations, but it is important to stress that it is the fine detail-that which derives from local context - that will help us to best understand how to deter illicit metal detecting.

\section{$<H 2>$ Incongruencies in Data}

These three sets of data have provided us with information that is not only distinctly different from any previous published data in its scope but also not comparable across the three sources. There are four areas where the data differs: purpose, accessibility, recording, and reporting. The data sources reflect datasets that have been gathered for different purposes. The FOI requests were reliant on police recording systems, which vary between forces. There are strict rules in terms of what is recorded as a crime, and the purpose of police data is to reflect recordable offences according to Home Office counting 
rules. The database is therefore massive, as it records all crime types. In contrast, the HE list was collated by an individual, largely in response to a specific police operationOperation Chronos - but with the aim of getting a sense of the national scale of illicit metal detecting. The FLO surveys were undertaken to reveal the extent to which the PAS as a whole was engaging with local law enforcement authorities and how this varied across counties. With different aims and objectives, it is not surprising that the content of each dataset differs significantly.

There are differences also in the accessibility of data on the respective systems. Both the FLO and the HE list were small-scale datasets that were collated by an individual and were specific to metal detecting and finds. We were able to access these because the former was collated by the first author and the latter was collated by Mark Harrison, with whom we have an excellent working relationship. In contrast, relying on the FOI responses to access police data relied on phrasing the request in such a way as to facilitate police staff understanding and compliance. Even so, it became apparent that the police databases are not fit for this purpose; details about modus operandi and other attributes of the crime event are often not available except by manual searches of thousands of potentially relevant cases. This seems in part due to poor database design and in part due to the aforementioned counting rules that provide limitations within which the police must record crimes.

This leads us to the third area, which demonstrates the distinct differences in data-namely, recording practices. The FLO survey addressed all issues that had come to the attention of the relevant officers, regardless of whether they had come to the attention of the police. The HE list was mostly built by keeping records on police activity, which makes the differences between this data source and the police responses to the FOI request an interesting reflection of the ways in which the recorded details are accessible at a later date. The police data reflect both reporting and recording practices. These issues are well documented in policing generally. ${ }^{69}$ Individuals and organizations may lack awareness of how and in what circumstances illicit metal detecting may be reported to police. Police must decide whether a reported incident is deemed recordable as crime under Home Office counting rules. ${ }^{70}$ These two issues combine to result in an undercount

\footnotetext{
${ }^{69}$ See, e.g., Levitt 1998.

${ }^{70}$ https://www.gov.uk/government/publications/counting-rules-for-recorded-crime
} 
in official crime statistics, known as the "dark figure" of crime. ${ }^{71}$ This will doubtless affect both the information available from the HE list and the FOI requests, whereas the FLO survey will likely be less affected by this problem, being a survey of already engaged professionals.

In practice, these differences have meant that, although each dataset has been able to provide a small part of the picture of illicit metal detecting, they cannot be used to cross-reference cases or to confirm overall figures. This once more draws our attention to the need for a consistent and regular recording of illicit metal detecting incidents - and, indeed, heritage crime more broadly. ${ }^{72}$

\section{CONCLUSIONS}

The implications of this research are clear: we cannot say with any degree of confidence what the nature and extent of illicit metal detecting is at present. This is important for two reasons. First, without reliable information about where and when illicit metal detecting is occurring, limited policing and community resources, which may otherwise be deployed to tackle the problem, will be unlikely to be justifiable at a time of tight budget constraints where priorities are many and varied. Second, without a body of evidence about illicit metal detecting, there is no baseline against which to assess the effectiveness of any preventive efforts launched. In other words, even where resources are found to tackle illicit metal detecting, there is no way at present of telling whether the problem lessens (or even increases) as a result of relevant interventions. Therefore, although the need for prevention of illicit metal detecting and other heritage crimes is something the authors are keen to draw attention to, arguably of greater immediate concern is the lack of coherent information in this sector. The authors have written further about the weakness of the available data in a recent article. ${ }^{73} \mathrm{~A}$ shared means of communication between heritage organizations, public institutions, and law enforcement communities is essential, and it is our belief that this is an issue that requires strategic coordination at the highest level in order to address this fundamental lack of knowledge and facilitate future crime

\footnotetext{
${ }^{71}$ See, e.g., Skogan 1977 .

72 C.f. Grove, Thomas, and Daubney 2018.

${ }^{73}$ Grove, Thomas, and Daubney 2018.
} 
prevention efforts. Of particular importance will be the consideration of models that offer best practice in an era of economic challenges and that make effective use of partnerships between heritage professionals and the public sector. ${ }^{74}$ Indeed, an increasing number of examples of best practice that involve multi-agency approaches to policymaking, compliance, and enforcement can be found in other areas, such as wildlife crime ${ }^{75}$ and illegal commercial fishing. ${ }^{76}$ Whilst the current age of austerity is one driving force for interdepartmental and multi-agency approaches to crime reduction, it should not be seen as the only one or the primary one; many members of the public are keen to protect their local heritage and are often willing to assist law enforcement authorities in collaborative efforts to reduce damage to heritage assets on a local level.

Indeed, it is without doubt that there have been great advances in efforts to tackle the issue of illicit metal detecting in England and Wales and of "heritage crime" more broadly. Revised sentencing guidelines for theft offences now oblige the courts of England and Wales to consider "damage to heritage assets" when sentencing those convicted of theft. ${ }^{77}$ Similarly, there are demonstrably closer working partnerships between different agencies-in particular, Historic England, the Historic Environment Record offices, the police, and the PAS; the HE list being a notable product of this coordination. Developing closer links are key features of both the 2020 PAS $^{78}$ and the 2017 Heritage and Cultural Property Crime National Strategic Assessment.

Against this backdrop of greater partnership, we have found, however, that there is a paucity of information and data about illicit metal detecting. Partly, this is due to remote sites and underreporting. However, a major part owes to the inaccessibility of the gathered reports, the incomplete picture that unofficial sources can give us, and the lack of systematic recording by law enforcement authorities. The latter is one of the concerns of the 2017 Heritage and Cultural Property Crime National Strategic Assessment, out of

\footnotetext{
${ }^{74}$ Kerr 2018.

75 Illes 2016.

${ }^{76}$ Petrossian and Clark 2014.

77 Sentencing Council, "Theft Offences Definitive Guidelines," 2015, https://www.sentencingcouncil.org.uk/wp-content/uploads/SC-Theft-Offences-Definitive-Guidelinecontent_FINAL-web_.pdf (accessed 19 March 2018).

${ }^{78}$ Lewis 2016 b.
} 
which it is hoped that improvements and developments in reporting and recording of intelligence will emerge. ${ }^{79}$

Nonetheless, this article has taken an initial foray into exploring trends in the data that are available. Whilst the collection of this data has not been a perfect process, it has provided an indication of our knowledge since the Nighthawking Survey of 2009. From this information, we have seen that illicit metal detecting is an ongoing problem, with reports disproportionately concentrated in some counties (Hampshire, Suffolk, Kent), at certain types of sites (settlements, hill forts), and even that individual sites are repeatedly victimized. This is important because we know that the identification of crime concentration patterns allows us to better target our limited crime prevention resources, drawing on local knowledge to develop an appropriate strategy. ${ }^{80}$

In this regard, the HE list has proved invaluable. Of course, the list was a response to one of the recommendations of the Nighthawking Survey that asked Historic England (formerly English Heritage) to maintain a central database of nighthawking incidents. ${ }^{81}$ However, it is clear that our detailed understanding of illicit metal detecting can only be enhanced through systematic and consistent recording of incidents by different police force areas and, indeed, through access to that information. This might be aided by a "flag" on the police recording system to facilitate the identification of heritage-related offences.

The Nighthawking Survey also made further recommendations that, if addressed, may result in a decrease in the level of nighthawking. ${ }^{82}$ These recommendations include providing more information to landowners so that they can identify nighthawking and know what to do when they encounter it; using available opportunities to publicize the positive aspects of responsible metal detecting and the negative effects of nighthawking; ensuring the PAS is fully funded so that links between archaeologists and metal detectorists are further strengthened; integrating metal detecting into the archaeological process, including development control briefs; and implementing changes recently introduced in Europe that increase the obligation on sellers of antiquities to provide

\footnotetext{
${ }^{79}$ Heritage and Cultural Property Assessment.

${ }^{80}$ Grove, Daubney, and Booth 2018.

${ }^{81}$ Oxford Archaeology 2009, 109.

82 Oxford Archaeology 2009, 166.
} 
provenances and establish legal title and urge eBay to introduce more stringent monitoring of antiquities with a UK origin that are offered for sale on their website.

These recommendations have been addressed, though not comprehensively, by a variety of approaches and initiatives. These include the publication and 2017 revision of guidance for landowners; ${ }^{83}$ mainstream media articles that promote responsible metal detecting and also highlight the impact of illicit metal detecting; the publication of a revised Code of Practice on Responsible Metal Detecting in England and Wales, ${ }^{84}$ conferences and academic articles on metal detecting and archaeology; ${ }^{85}$ continued funding for the PAS; and the development of partnerships between FLOs and officers within local police forces.

Yet, in spite of these efforts, the current statistics show that our knowledge of illicit metal detecting is actually increasing (though it is unclear whether this reflects an increase in incidents or simply a greater awareness, reporting, and policing of the problem). There is, however, one recommendation for which there has been very little action: the attempt to reduce the trade in illicit antiquities by reforming the online trade in unprovenanced antiquities of UK origin. This includes establishing and proving legal title to finds. In the absence of regulations, there is a substantial volume of antiquities offered for sale each day in the UK, some of which is of legal origin, some of which would undoubtedly be of illicit origin, and the vast majority of which is of uncertain legal status. ${ }^{86}$ This corpus of material has recently been described as "floating culture" - material that is, in effect, dislodged from context and now ebbing and flowing across the antiquities market. ${ }^{87}$ While the Nighthawking Survey singled out eBay as a place where policy change was needed, today the market includes a much wider range of online outlets, private messaging platforms, and the "invisible market" where transactions take place face to face. Given the explicit links between damage to archaeological sites and the trade in antiquities ${ }^{88}$-and the limited success of initiatives established in response to the Nighthawking Survey to reduce illicit metal detecting-it would seem that attention now needs to focus on the

\footnotetext{
${ }^{83}$ Guidance for Landowners.

${ }^{84}$ Code of Practice.

${ }^{85}$ Campbell and Thomas 2013; Lewis 2016b, 11; Grove, Thomas, and Daubney 2018.

${ }^{86}$ Bland 2009.

${ }^{87}$ Daubney 2017.

${ }^{88}$ Brodie 2017.
} 
issue of uprovenanced antiquities of UK origin being offered for sale, particularly online. Of course, this conclusion, which rests on the evidence from England and Wales, does highlight the transnational issue of the Internet market in stolen and trafficked antiquities, which Neil Brodie has recently described as being "largely out of control." 89 The situation we have described in the UK is, accordingly, a symptom of a much larger issue.

\section{$<$ RFN>BIBLIOGRAPHY}

Barford, P. 2010. "Archaeology, Collectors and Preservation: A Reply to David Gill." Papers from the Institute of Archaeology 20: 16-23. doi:http://doi.org/10.5334/pia.335.

Biderman, A. D., and A. J. Reiss Jr, 1967. “On Exploring the 'Dark Figure' of Crime." Annals of the American Academy of Political and Social Science 374, no. 1: 1-15.

Bland, R. 2005. "A Pragmatic Approach to the Problem of Portable Antiquities: The Experience in England and Wales." Antiquity 79, no. 304: 440-47.

Bland, R. 2009. "The United Kingdom as a Source Country: Some Problems in Regulating the Market in UK Antiquities and the Challenge of the Internet." In Criminology and Archaeology: Studies in Looted Antiquities, edited by Simon Mackenzie and Penny Green, 83-102. Oxford: Hart Publishing.

Brindle, T . 2014 . The Portable Antiquities Scheme and Roman Britain . London : British Museum .

Brodie, N. 2017. How to Control the Internet Market in Antiquities? The Need for Regulation and Monitoring, Antiquities Coalition Policy Brief no. 3. http://thinktank.theantiquitiescoalition.org/how-to-control-the-internet-marketin-antiquities-the-need-for-regulation-and-monitoring/ (accessed 12 March 2018).

Campbell, S., and S. Thomas, eds. 2013. "Portable Antiquities: Archaeology, Collecting, Metal Detecting." Internet Archaeology 33

Coombes, M., D. Bradley, L. Grove, S. Thomas, and C. Young. 2012. The Extent of Crime and Anti-Social Behaviour Facing Designated Heritage Assets. Glasgow: Scottish Centre for Crime and Justice Research. http://www.sccjr.ac.uk/wp-

${ }^{89}$ Brodie 2017, 12. 
content/uploads/2012/12/Heritage-Crime-England1.pdf (accessed 18 January 2018)

Daubney, A. 2016. Portable Antiquities, Palimpsests, and Persistent Places. Leiden: Sidestone Press.

Daubney, A. 2017. "Floating Culture: The Unrecorded Antiquities of England and Wales." International Journal of Heritage Studies 23, no. 9: 785-99. doi:10.1080/13527258.2017.1325770.

Deckers, P., A. Dobat, N. Ferguson, S. Heeren, M. Lewis, and S. Thomas. 2018. "The Complexities of Metal Detecting Policy and Practice: A Response to Samuel Hardy, 'Quantitative Analysis of Open-Source Data on Metal Detecting for Cultural Property' (Cogent Social Sciences 3, 2017)." Open Archaeology 4, no. 1: 322-33. doi:10.1515/opar-2018-0019

Department for Culture, Media, and Sport (DCMS). 2013. Scheduled Monuments and Nationally Important but Non-Scheduled Monuments. London: DCMS. https://www.gov.uk/government/uploads/system/uploads/attachment_data/file/ 249695/SM_policy_statement_10-2013_2_.pdf (accessed 22 February 2018).

Dobinson, C., and S. Denison. 1995. Metal Detecting and Archaeology in England. London: English Heritage / Council for British Archaeology.

Fincham, D. 2008. "A Coordinated Legal and Policy Approach to Undiscovered Antiquities: Adapting the Cultural Heritage Policy of England and Wales to Other Nations of Origin." International Journal of Cultural Property 15, no. 3: 347-70.

Gill, D. 2010. "The Portable Antiquities Scheme and the Treasure Act: Protecting the Archaeology of England and Wales?" Papers from the Institute of Archaeology 20: 1-11. doi:10.5334/pia.333.

Grove, L. 2013. "Heritocide? Defining and Exploring Heritage Crime." Public Archaeology 12, no. 4: 242-54. doi:10.1179/1465518714Z.00000000046.

Grove, L., A. Daubney, and A. Booth. 2018. “Identifying Sites at Risk from Illicit Metal Detecting: From CRAVED to HOPPER." International Journal of Heritage Studies no. 10: $1038-1052$ doi:10.1080/13527258.2018.1475408.

Grove, L., S. Thomas, and A. Daubney. 2018. "Fool's Gold? A Critical Assessment of Sources of Data on Heritage Crime." Disaster Prevention and Management: An International Journal 
Hardy, S. 2017. "Quantitative Analysis of Open-Source Data on Metal Detecting for Cultural Property: Estimation of the Scale and Intensity of Metal Detecting and the Quantity of Metal-Detected Cultural Goods." Cogent Social Sciences 3, no. 1: 1-49. doi:10.1080/23311886.2017.1298397.

Historic England. 2017. Guidance for Sentencers: Heritage Crime. 1 February. https://historicengland.org.uk/images-books/publications/heritage-crimeguidance-sentencers/ (accessed online 22 February 2018).

Illes, A. 2016. Wildlife Crime in the United Kingdom: In-depth Analysis for the ENVI Committee. Brussels: European Parliament.

Johnson, D., and E. Hampson. 2015. "Utilising the UK Freedom of Information Act 2000 for Crime Record Data: Indications of the Strength of Records Management in Day to Day Police Business." Records Management Journal 25, no. 3: 248-68.

Kerr, J. 2018. "The State of Heritage and Cultural Property Policing in England and Wales, France and Italy." European Journal of Criminology doi:10.1177/1477370818803047.

Levitt, S. D., 1998. "The Relationship between Crime Reporting and Police: Implications for the Use of Uniform Crime Reports." Journal of Quantitative Criminology 14, no. 1: 61-81.

Lewis, M. 2016a. “A Detectorist's Utopia? Archaeology and Metal-Detecting in England and Wales." Open Archaeology 2: 127-39.

Lewis, M. 2016b. The Portable Antiquities Scheme Annual Report 2016. London: British Museum.

Oxford Archaeology. 2009. Nighthawks and Nighthawking. Damage to Archaeological Sites in the UK and Crown Dependencies Caused by IIlegal Searching and Removal of Antiquities. Strategic Study Final Report. Oxford: Oxford Archaeology. http://www.helm.org.uk/guidance-library/nighthawks-nighthawking/ (accessed 30 January 2018).

Petrossian, G., and R. Clarke. 2014. "Explaining and Controlling Illegal Commercial Fishing: An Application of the Craved Theft Model." British Journal of Criminology 54, no. 1: 73-90. 
Shelbourn, C. 2014a. "A Tale of Two Prosecutions: Prosecuting Heritage Crime in England and the United States, a Cautionary Tale." Art, Antiquity and Law 19, no. 3: 25364.

Shelbourn, C. 2014b. "Improving the Treatment of Heritage Crime in Criminal Proceedings: Towards a Better Understanding of the Impact of Heritage Offences." In Heritage Crime: Progress, Prospects and Prevention, edited by L. Grove and S. Thomas, 188205. Basingstoke, UK: Palgrave Macmillan.

Skogan, W. G. 1977. "Dimensions of the Dark Figure of Unreported Crime." Crime and Delinquency 23, no. 1: 41-50.

Thomas, S. 2009. "The Relationships between Archaeologists and Metal-detector Users in England and Wales: Impact of the Past and Implications for the Future." Unpublished PhD dissertation, Newcastle University.

Thomas, S. 2010. "Nighthawks and Dayhawks: Heritage Thieves with Metal Detectors." The Archaeologist 77: 16-17.

Thomas, S. 2012. "How STOP Started: Early Approaches to the Metal Detecting Community by Archaeologists and Others." In Community Archaeology: Themes, Methods and Practices, edited by G. Moshenska and S. Dhanjal, 42-57. Oxford: Oxbow Books.

Thomas, S. 2013. "Editorial-Portable Antiquities: Archaeology, Collecting, Metal Detecting." Internet Archaeology 33.

Wilson, P., and M. Harrison. 2013. Three years on from “The Nighthawking Survey': innovations in heritage protection. Internet Archaeology 33 